\title{
Effective "On-Boarding": Transitioning from Trainee to Faculty
}

\author{
Jillian Gustin, M.D. and James A. Tulsky, M.D.?
}

\begin{abstract}
The transition from trainee to junior faculty member can be both exciting and daunting. However, a paucity of medical literature exists to help guide new faculty in this transition. Therefore, we adapted work from the business management literature on what is referred to as "on-boarding," effectively integrating and advancing one's position as a new employee. This article outlines strategies for cultivating one's own on-boarding as a junior faculty member at large academic medical centers. These strategies are extrapolated from management practices, culled from the medical literature on developing and retaining junior faculty, and, finally, borrowed from the hard-won knowledge of junior and senior faculty members. They advise new faculty to: (1) start early, (2) define your role-“managing yourself," (3) invest in/secure early wins, (4) manage your manager, (5) identify the "true (or hidden)" organizational culture, (6) reassess your own goals-"look in the rearview mirror and to the horizon," and (7) use your mentors effectively. These strategies provide a roadmap for new faculty members to transition as effectively as possible to their new jobs.
\end{abstract}

\section{Introduction}

M AKING THE TRANSITION from fellow to faculty member ought to be easy. Medical school, residency, and fellowship teach physicians to transition from one setting to another. We find ourselves on a different medical service every month and frequently move several times between cities and hospitals before that training is completed. However, the evolution from trainee to junior faculty member presents unique challenges and prior experiences moving from one rotation to another may not adequately prepare young physicians for this change. The responsibilities, time allocation, and financial structures are so different that without strong mentorship many junior faculty find themselves lost in their first months, or even years. ${ }^{1-3}$

Given the importance and frequency of these transitions, we were surprised to find that scant research sheds light on this issue. There is even a paucity of experiential literature that might guide junior faculty on how to effectively start a new academic job or to help academic institutions best assist and mentor young doctors in their early years. ${ }^{2-5}$ Therefore, we explored the management literature on what is referred to as "on-boarding," effectively integrating and advancing one's position as a new employee. ${ }^{6}$ Since the average hospital loses roughly half of its new recruits within 5 years of hiring, some health systems have noticed this work and have begun to look at how to effectively on-board new physicians as a means to improve retention. ${ }^{2,7}$ On-boarding strategies, however, are by no means standard protocol for academic centers.

This article outlines strategies for cultivating one's own onboarding as a junior faculty member at an academic medical center. Although we are writing this for the palliative care community, these strategies generalize to all physicians starting academic faculty jobs. They are extrapolated from business management practices, culled from the medical literature on developing and retaining junior faculty, and, finally, borrowed from the hard-won knowledge of junior and senior faculty members, including ourselves. The strategies include: (1) starting early; (2) defining your role-_managing yourself"; (3) investing in and securing early wins; (4) managing your manager-"managing up"; (5) identifying the true (or "hidden") organizational culture; (6) reassessing your own goals- "looking in the rearview mirror and to the horizon"; and (7) using your mentors effectively.

\section{Start Early}

Most junior faculty enjoy little time to ease into their new jobs. In some cases, they are quickly immersed into busy clinical services or teaching schedules. New faculty have little

\footnotetext{
${ }^{1}$ Center for Palliative Care, Department of Internal Medicine, The James Cancer Hospital and Solove Research Institute, The Ohio State University, Columbus, Ohio.

${ }^{2}$ Center for Palliative Care, Department of Medicine, Duke University and Durham VA Medical Center, Durham, North Carolina.

Accepted April 29, 2010.
} 
opportunity to get to know their colleagues or their new institution. Survival may be the primary goal for their first few weeks at work. Broad goals on how best to integrate into a new program are initially of less importance compared to finding a patient in the building or learning to use the order entry system. Thus effective on-boarding is often hampered by immediate responsibilities when starting a new job.

"Starting early" means getting to know your organization prior to your start date. ${ }^{8}$ Ideally, it includes: (1) minimizing outside distractions, (2) identifying key stakeholders, and (3) developing credibility with powerful first impressions. By adopting these strategies, you will begin to lay the groundwork for integration into the program before your initial responsibilities take precedence.

\section{Minimize distractions}

Two potential distractions may adversely affect onboarding. The first is coping with the challenges of relocating to a new city. ${ }^{8}$ Some institutions provide assistance to help you with the move-so make sure to ask about these resources. Others provide little assistance and may give you minimal transition time prior to your start date. On-boarding effectively is more difficult when you are also worried about movers arriving, school and daycare options, or being at home to meet the cable guy. If possible, give yourself ample time to settle into your new location prior to starting your new job.

The second potential distraction is the challenge of setting up your office and getting to know the hospital systems. ${ }^{8,9}$ Once you are engrossed at work, you will have little time to organize files, unpack boxes, set up your computer, or learn your hospital's electronic medical documentation. These tasks must also be done early and expeditiously.

\section{Identify key stakeholders}

To become acquainted with the inner workings of your program, identify key stakeholders and set up opportunities to meet with each of them individually. ${ }^{8,9}$ The program's organizational chart may help you identify these people. If it is not available, meet with representatives from various constituencies (e.g., your boss, physicians, nurses and interdisciplinary colleagues, administrative support staff), and ask them with whom else you should meet. ${ }^{8,9}$ Palliative care is often organized differently than other specialties so the key stakeholders may include individuals in other departments (e.g., geriatrics), organizations (e.g., affiliated hospice programs), etc.

Your goal in meeting with these key stakeholders is to learn how the program functions (including its strengths and weaknesses) and the expectations of you as a new member of the team, both of which may not have been elucidated during the interview process. ${ }^{10}$ Each stakeholder will provide their perspective on the program's history, process of change and decision-making as well as the strategic plan for the future. For instance, does your boss believe decision-making is democratic while your physician colleagues and nurses see it as hierarchical? Or, do the nurse practioners have few clinical expectations of you because they see themselves as independent practitioners as opposed to physician-extenders? Meeting with stakeholders individually will prepare you far better for what lies ahead. ${ }^{10}$

\section{Develop credibility with a powerful first impression}

Starting early can create a powerful first impression of commitment and respect. 9,11 As an "unknown quantity" all communication will fall under the microscope. Ensure that no key stakeholder has been missed. What you may consider a minor oversight such as forgetting to meet with the chaplain may be perceived as your lack of respect for the role of chaplaincy on the interdisciplinary team. By intentionally requesting time to meet with various stakeholders and hear their perspectives, you will send a strong message that you respect their knowledge and see them as a potential guide and mentor.

\section{Define Your Role - “Manage Yourself”}

The next step to effective on-boarding is to further delineate your role and responsibilities. If you took advantage of starting early and met with all the various stakeholders, you should have a good understanding of how the program works and your perceived role in it. Now you can constructively consider what interests you and how these interests fit with the program's strategic plan, your new colleagues' projects, and your institution's promotion criteria. For many early career academics, interests are defined broadly and focusing on any one raises the fear that doors will close on other interests. As one colleague said, "Academia is like a candy store-there are so many options that it can be hard to chose." Use the experience of colleagues and mentors to help clarify your interests and the expectations of the job while avoiding territorial issues or reinventing the wheel. ${ }^{12}$ At the same time, closely consider your own boundaries so that you can make clear to yourself and your colleagues what you can deliver. For some, this may require further reflection on work-life balance needs.

\section{Invest In and Secure Early Wins}

You want to quickly develop credibility that you can meet colleagues' expectations and perform your responsibilities. Thus, it is important to invest your energy into projects that will produce "early wins." 13,14 Or, alternatively, "grab the low-hanging fruit." Early wins may be concise scholarly projects, rapidly developed educational programs or a review paper based on previously given lectures. If possible, build upon prior accomplishments as a fellow.

Gap analysis and SMART goals are two tools that can help achieve the early wins. Gap analysis is a set of questions (i.e., "Where are you versus where do you want to be," and "What steps to you need to take to close that gap?") to help you identify the necessary steps for achieving your goal. ${ }^{12}$ For instance, if your goal is to develop a palliative care curriculum for residents, a gap analysis would include identification of the palliative care competencies already incorporated into the residency curriculum, recognition of the missing palliative care competencies, and development of the knowledge and skills necessary to address the deficiencies. SMART goals (Specific, Measurable, Attainable, Relevant, Time-bound) can help you conceptualize specific smaller objectives as steps towards achieving your overriding goal. ${ }^{15}$ Using the example above, one specific objective could be the use by every resident of the equianalgesic chart to provide better pain control. This goal could be achieved in one didactic lecture and 
distribution of a pocket card, and measured by a post-test. Creating multiple SMART goals will help you close identified gaps.

\section{Manage Your Manager-“Managing Up”}

One of your most important relationships at work is with your boss. If you have followed the roadmap above, you should know your boss's perspective on the future of the program and your future within it. For both of you to perform your jobs effectively, you must nurture that relationship. Despite the hierarchical nature of the relationship, as the new faculty member you need to be proactive and manage your manager. ${ }^{16-18}$

"Managing up" requires, first and foremost, that you understand your boss and the context within which he or she works. ${ }^{16,18}$ What goals does he or she have for the palliative care program? What are his or her professional goals, strengths and weaknesses and preferred working style? How does your boss like to receive information?

"Managing up" also requires that you know your own strengths, weaknesses, preferred working style, and boundaries. ${ }^{16}$ You need to develop and maintain a style that fits both your needs and is also capable of adjusting to fit your boss's preferences. For instance, you may prefer to present new ideas to your boss during faculty meeting discussions while your boss wants written proposals. It can be helpful to delineate your similarities and differences in working styles as well as your limitations and boundaries so that mutual expectations can be outlined.

Finally, "managing up" means that you respect your boss's time and use him or her as a resource selectively. ${ }^{16-18} \mathrm{Ne}-$ gotiate how and when you will communicate and press for regular meetings. As you "on-board," you want to be considered dependable, consistent and proactive. Your ideas are more likely to be considered by your boss if she or he is ready to listen.

\section{Identify the True (or "Hidden") Organizational Culture}

After approximately 3-6 months at your new institution, you may realize that the expectations formed during your early meetings with stakeholders do not fit the current reality. This should not be surprising. It often takes time immersed in an institution to gain insight into the true or "hidden" culture. The next step to effective on-boarding is to reassess the organizational culture and your niche within it. ${ }^{19,20}$

The process of identifying the true or hidden organizational culture can be achieved through self-reflection and discussions with colleagues. ${ }^{19,20}$ Ask the following questions: What are the successful ways in which my colleagues get work completed? How is time valued and managed? How is information shared? How are decisions truly made? How do ideas get adopted? What is valued by the program versus the institution? How are my colleagues held accountable for their actions? Who is the source of information regarding available resources? What are the territorial issues? Consider setting up meetings with colleagues to discuss these questions. Hopefully, you have become part of the culture and have engendered enough trust to receive forthright answers.

After answering some, if not all, of these questions, consider again your place in the organizational culture. ${ }^{19}$ Find your program's strengths on which to capitalize (e.g., multi- ple physician specialties, robust outpatient pain clinic, etc.) and identify the institution's unique strengths (e.g., crossdiscipline collaboration, proximity to a divinity school, etc.) Get to know your program and your institution as an insider to help you consider where you fit into the bigger picture.

\section{Reassess Your Own Goals-“Look in the Rearview Mirror and to the Horizon"}

After approximately 6 months of assimilation into the organization culture, you need to align your current perspective with initial expectations. By looking at what you have achieved and what you hope to achieve, you will further define your niche within the organization and your future goals. Start by "looking in the rearview mirror" to see how far you have come. ${ }^{21,22}$ What have been your accomplishments or challenges with early wins, clinical work, role definition within the program and the institution, and relationships with your colleagues?

Consider meeting with key stakeholders again to plot your horizon. ${ }^{22,23}$ Ask them to identify your successes and challenges and where they see you making the greatest contribution in the future. Then, use gap analyses and SMART goals to take the gathered information and map out your horizon. ${ }^{23}$ You will likely repeat this process many times over your career. Many business strategists suggest performing gap analyses and SMART goals every 6 months to 1 year. ${ }^{23}$ With each reflection, reassess your working style, your desired niche and your work-life balance.

\section{Use Your Mentors Effectively}

Effective mentoring bolsters academic success in such areas as career advancement, publication productivity and grant funding. ${ }^{24,25}$ Mentoring can also prove invaluable for onboarding. If you are lucky, your mentor will act as your champion by facilitating your introduction to your new institution and your progress at the early stages of your career. However, in most cases, you will need to take an active role in guiding the mentoring relationship. ${ }^{24,26}$ A recent article written from the perspective of the mentee offers the following key points on using your mentor(s) effectively-another form of "managing up." 24

\section{Prepare for the mentoring relationship}

You will have more fruitful discussions with your mentor if you have reflected on and defined your goals and challenges. ${ }^{24}$ Take the perspective you gained in "managing oneself" and "looking in the rearview mirror and to the horizon" to identify areas in which you need mentoring. Make sure to consider all the various domains involved in your work such as work-life balance, networking, establishing goals, relationship building, institutional understanding, research, teaching and clinical skills. ${ }^{24,26}$

\section{Pick your mentors carefully}

Mentors should be available, accessible, and experienced. ${ }^{24}$ It is often hard to find all of the qualities you desire in one person. Thus, it is reasonable to have more than one mentor. ${ }^{24}$ Cast your search widely and be open to different nontraditional forms of mentoring such as peer-based and distance mentoring and mentoring committees. ${ }^{22,27,28}$ Mentors in 
different medical subspecialties (e.g., critical care), outside medicine (e.g., cognitive psychology) or at another institution may prove beneficial, particularly if there are few (if any) senior-level palliative care practitioners at your own institution. Some institutions assign mentors while others foster mentors that develop organically based on mutual interests (identified through word-of-mouth, publications, conferences, etc.). Regardless, ensure that the mentor(s) you pick have the interests and qualities necessary to help you develop.

\section{Nurturing the mentoring relationship}

Set up an initial meeting and negotiate how best to communicate and agree on a structure for future meetings. ${ }^{24} \mathrm{Be}$ clear on your mentoring needs and communicate those needs to your mentor. ${ }^{24}$ Ask for feedback and discuss the efficacy of your mentoring relationship as it develops. ${ }^{24}$ Taking responsibility for the relationship includes identifying if and when the relationship is no longer helpful. ${ }^{24}$ Personality clashes, generational tensions, power dynamics are all reasons that mentoring relationships fail. 2,3,25,26 Furthermore, as your career develops, your mentoring needs will change. ${ }^{24}$ By choosing your mentors carefully initially and cultivating the relationship, you will ensure the effectiveness of you and your mentors' interactions.

\section{Conclusion}

Finally, palliative care has its own set of unique challenges to on-boarding. How will the long-term caring for patients with life-limiting illnesses impact you emotionally? How will you manage the distress of trainees during their first encounters with dying patients? How will you manage the oftentimes divergent views of an interdisciplinary team? Who will you go to for advice if you are in an institution where there are few palliative care faculty? There are no easy answers. Hopefully, these are skills you have learned in fellowship. If not, take advantage of sessions at annual meetings and your professional peer group to reflect on these questions and share with others in similar situations.

Sometimes, despite your best intentions, you and your new job may not be the right fit. A wise colleague said,

My advice would be to remember that if you end up not loving your job, just remember that you can always change it. Either way, you will have learned new and valuable skills, met new people/contacts, and probably opened up new doors (without even realizing it).

Nonetheless, by following the suggested on-boarding strategies above, you will have given yourself the best chance of starting off on the right foot in your first year as a junior faculty member. With the input of your boss and your mentor(s), set yourself concrete milestones that constitute success in your institution and for you personally. Most importantly, take responsibility for your own on-boarding and take your time to learn about yourself, your program, and your institution.

\section{References}

1. Farley H, Casaletto J, Ankel F, Young KD, Hockberger R: An assessment of the faculty development needs of junior clinical faculty in emergency medicine. Acad Emerg Med 2008;15:664-668.

2. Chapman A, Guay-Woodford L: Nurturing passion in a time of academic climate change: The modern-day challenge of junior faculty development. Clin J Am Soc Nephrol 2008;3: 1878-1883.

3. Bickel J, Brown AJ: Generation X: Implications for faculty recruitment and development in academic health centers. Acad Med 2005;80:205-210.

4. Applegate WB, Williams ME: Career development in academic medicine. Am J Med 1990;89:263-267.

5. Morahan PS, Gold JS, Bickel J: Status of faculty affairs and faculty development offices in U.S. medical schools. $\underline{\text { Acad }}$ Med 2002;77:398-401.

6. Bradt G, Check J, Pedraza J: The New Leader's 100-Day Action Plan: An On-Boarding Process for Leaders at Every Level. Hoboken, NJ: John Wiley \& Sons, Inc., 2006.

7. Thorndyke L, Gusic M, George J, Quillen D, Milner R: Empowering junior faculty: Penn State's faculty development and mentoring program. Acad Med 2006;81:668-673.

8. Bradt G, Check J, Pedraza J: You must start before day one: Especially with your Boss and key stakeholders. In: The New Leader's 100-Day Action Plan: An On-Boarding Process for Leaders at Every Level. Hoboken, NJ: John Wiley \& Sons, Inc., 2006, pp. 51-76.

9. Sindell M, Sindell T: Case the Joint. In: Sink or Swim! New Job. New Boss. 12 Weeks to Get it Right. Avon, MA: Adams Media, 2006, pp. 29-50.

10. Goldsmith JA, Komlos J, Schine Gold P: The life of the assistant professor. In: The Chicago Guide to Your Academic Career: A Portable Mentor For Scholars From Graduate School Through Tenure. Chicago: The University of Chicago Press, 2001, pp. 135-160.

11. Bradt G, Check J, Pedraza J: Bradt G, Check J, Pedraza J: Takc control of Day One: Make a powerful first impression. In: The New Leader's 100-Day Action Plan: An On-Boarding Process for Leaders at Every Level. Hoboken, NJ: John Wiley \& Sons, Inc., 2006, pp. 81-90.

12. Sindell M, Sindell T Sindell M, Sindell T: Get a firm grip. In: Sink or Swim! New Job. New Boss. 12 Weeks to Get it Right. Avon, MA: Adams Media, 2006, pp. 51-74.

13. Bradt G, Check J, Pedraza J: Invest in Early Wins to build team confidence. In: The New Leader's 100-Day Action Plan: An On-Boarding Process for Leaders at Every Level. Hoboken, NJ: John Wiley \& Sons, Inc., 2006, pp. 127-134.

14. Watkins M: Secure early wins. In: The First 90 Days: Critical Success Strategies for New Leaders at All Levels. Boston, MA: Harvard Business School Press, 2003, pp. 79-102.

15. Bradt G, Check J, Pedraza J: Use Key Milestones to Drive Team Performance. In: The New Leader's 100-Day Action Plan: An On-Boarding Process for Leaders at Every Level. Hoboken, NJ: John Wiley \& Sons, Inc., 2006, pp. 113-126.

16. Gabarro J, Kotter J: Managing your boss: A compatible relationship with our superior is essential to being effective in your job. Harvard Business Review 1980;58: 92-100.

17. Sindell M, Sindell T: Sindell M, Sindell T: Buckle down. Sink or Swim! New Job. New Boss. 12 Weeks to Get it Right. Avon, MA: Adams Media, 2006, pp. 75-100.

18. Watkins M: Negotiate success. In: The First 90 Days: Critical Success Strategies for New Leaders at All Levels. Boston, MA: Harvard Business School Press, 2003, In: The First 90 Days: Critical Success Strategies for New Leaders at All Levels. Boston, MA: Harvard Business School Press, 2003, pp. 103-128.

19. Sindell M, Sindell T: Climb onto the observation deck. In: Sink or Swim! New Job. New Boss. 12 Weeks to Get it Right. Avon, MA: Adams Media, 2006, pp. 129-150. 
20. Watkins M: Keep your balance. In: The First 90 Days: Critical Success Strategies for New Leaders at All Levels. Boston, MA: Harvard Business School Press, 2003, pp. 203-224.

21. Perform a reality check. In: Sink or Swim! New Job. New Boss. 12 Weeks to Get it Right. Avon, MA: Adams Media, 2006, pp. 247-272.

22. Sindell M, Sindell T: Look in the rearview mirror. In: Sink or Swim! New Job. New Boss. 12 Weeks to Get it Right. Avon, MA: Adams Media, 2006, pp. 223-246.

23. Sindell M, Sindell T: Map your coorindates. In Sink or Swim! New Job. New Boss. 12 Weeks to Get it Right. Avon, MA: Adams Media, 2006, pp. 199-222.

24. Zerzan J, Hess R, Schur E, Phillips R, Rigotti N: Making the most of mentors: A guide for mentees. Acad Med 2009; 84:140-144.

25. Sambunjak D, Straus SE, Marusic A: Mentoring in academic medicine: A systematic review. JAMA 2006;296:1103-1115.

26. Sambunjak D, Straus SE, Marusic A: A systematic review of qualitative research on the meaning and characteristics of mentoring in academic medicine. J Gen Intern Med 2010; 25:72-78.

27. Leslie K, Lingard L, Whyte S: Junior faculty experiences with informal mentoring. Med Teach 2005;27:693-698.

28. Pololi LH, Knight SM, Dennis K, Frankel RM: Helping medical school faculty realize their dreams: An innovative, collaborative mentoring program. Acad Med 2002;77: 377-384.

Address correspondence to: Jillian Gustin, M.D. Center for Palliative Care The Ohio State University Atwell Hall, Room 246 453 West 10th Avenue Columbus, $\mathrm{OH} 43210$

E-mail: jillian.gustin@osumc.edu 
